\title{
Wining the Talent War via Effective Employee Engagement: A Case Study
}

\section{Maniam Kaliannan* and Samuel Narh Adjovu}

School of Business, University of Nottingham Malaysia

\begin{abstract}
As the corporate sector entrenches itself among the players of the global economy, more sophisticated strategies and novel business trends are required so as to enhance profitability and lower business costs. It is against this backdrop that the researchers undertook this study to explore possible alternatives of addressing the talent war rather than the orthodox methods. A multinational telecommunication company located in Ghana (Mobile Telecommunication Network, MTN Ghana) was selected as a case, due to its competitiveness and world presence, especially for its dominance in Africa.

With substantive review of the literature, five thematic effective engagement variables were discovered: the work environment, supervisor-employee relationship, job satisfaction, HRM Practices, and organization culture. A quantitative approach was adopted as the main tool to gather 137 valid responses from employees of MTN Ghana. Some comprehensive interviews were also conducted to saturate the robustness of the findings. Therefore, the methodological approach to this research outcome could be best described as triangulation. Interestingly, the findings were insightful, intriguing and competitively viable.

The role of human capital in the success of every giant firm certainly could not be overemphasized. Obviously, our findings shed amazing light on why the company is beating its industry competitors like Tigo and Vodafone hands down. The company is committed to her employees and the inverse is also true-commitment begets engagement. Though, few gaps were identified, on a whole the talent war is a done deal when the engagement strategies are sound.
\end{abstract}

Keywords: Effective employee engagement; Talent management; Talent war; Paper type: case study

\section{Introduction}

"In the war for talent, even firms that are not interested would have no choice but to partake and it's only those firms that are prepared beforehand that would prevail"-Gladwell

The on-going war for talent seems to be building momentum progressively and creating the need for concern among top firms as the obvious realities of employee attrition stare senior management officers in the face. Thus, most employees rather feel robbed of physical, emotional, mental and even spiritual energy by their respective companies [1].

A survey conducted by Srinivasan Pillay, an assistant clinical professor and a psychiatrist at Harvard Medical School via random sampling of 72 senior executives discovered almost all of them admitted some level of burnout signals. In broader terms, just about 30 percent of employees in America are highly engaged to their work as reported by Gallup 2013. In global terms, among 142 countries the engaged proportion of employees is 13 percent. To most employees, the dispiriting and depleting nature of work is obviously taking an endless toll on their health. Not only are employees getting choked by the disequilibrium created in modern work setting and quality of family life but also the peaking need for organizations to remain competitive in order to survive [2]. When Gallup interviewed most of the CEO's they acknowledged that the constant demand for time, puts them in a position where they are compelled to pay more of their mental and emotional resilience than they ever bargained.

Interestingly, a survey conducted by Harvard Business Review which involved 12,000 dominantly white collar employees across varied firms and industries which also include employees of two energy projects- one manufacturing company of 6000 employees and the other, a financial services firm of 2,500 employees. A homogeneous outcome was found to exist among the three populations [3]. Employee satisfaction and productivity level proved to be significantly linked with their mental, emotional, physical and spiritual equilibrium. Obviously, the pattern of engagement gets stronger as these core needs are being supported and inversely, it reduces the perceived stress level among employees. In a meta-analysis of 263 research studies among 192 companies to correlate engagement components such as enthusiasm, passion, commitment, involvement and focused effort with corporate performance, it was discovered organizations that fall within the top quartile for engaged employees, compared with the bottom quartile, achieved 22 percent higher profitability, 10 percent higher customer satisfaction, 28 percent less theft and 48 percent fewer safety issues. It comes as no surprise that in the surveys mentioned above, a happy, engaged workforce translates into high productivity, low turnover and strong internal branding. The emotional attachment of employees in relation to their work environment influences speed and the overall job clarity. However, more profound evidence lies in the findings of [4] where it was discovered that high employee engagement had led to a reduction of 25 percent lower turnover in high attrition firms and that of 65 percent lower turnover in low attrition firms. Additionally, it revealed the capacity of employee engagement leading to "job recreation" where employees have the natural flow to do what they do best, thereby invoking a sense of satisfaction in their job role. Besides, it reduces the relentless pressure on HR to make itself relevant via defensive and

*Corresponding author: Maniam Kaliannan, School of Business, University of Nottingham, Malaysia Jalan Broga, 43500 Semenyih, Malaysia, E-mail: maniam.kaliannan@nottingham.edu.my

Received December 24, 2014; Accepted February 02, 2014; Published February 15,2015

Citation: Kaliannan M, Adjovu SN (2015) Wining the Talent War via Effective Employee Engagement: A Case Study. J Bus Fin Aff 3: 132. doi:10.4172/21670234.1000132

Copyright: (c) 2015 Kaliannan M, et al. This is an open-access article distributed under the terms of the Creative Commons Attribution License, which permits unrestricted use, distribution, and reproduction in any medium, provided the original author and source are credited. 
retaliatory strategies. Defensively, they are compelled to alter internal human resource practices such as increasing salaries and benefits as well as employee training. On the retaliatory side, actions might be taken directly or indirectly to threaten the departing employees or the firm to which they are hired. For instance, an aggressive enforcement of non-compete clauses by managers. An epitome of such case was when Microsoft Corporation filed a lawsuit that prohibit its vice president from carrying out a specific project offered by Google Incorporated in the year 2005 [3]. Finally, effective employee engagement could be a strategic tool in creating organizational good will [5] argues that strong internal relationship among employees and their supervisors tend to build mutual cohesiveness that project the external brand of the firm.

Nonetheless, the influx of researches carried on the topic was tilted towards the western context with rare examples within the jurisdiction of Africa, especially relating to Ghana. To saturate the robustness of our fact findings, the framework had been underpinned by a rigorous selection of the variables endorsed by the literature [6]. Our optimism resides in the resourcefulness of the findings in enriching academic literature as well as building the knowledge pool of professionals. All in all, this paper presents an explicit outlook of the relevant literature that backs our study, the methodological approach, and finally, the outcomes clearly dissected. A comprehensive elucidation of the findings proceeds then after in the manner that draws the reader into the flow of the presentation. The discussion of the findings and the possible implications were critically assessed whilst the research limitations were also evaluated on their overall impact.

\section{Literature Review}

"As the corporate ship takes on water, sinking deep into the financial maelstrom, the fate of the deckhands, cooks and cabin boys we cannot guarantee...but surprisingly, there came an order from the captain for preparation of life rafts for the group whose lives we dare not sacrifice-the performance drivers"- [7].

The official launching of the concept, "talent war", occurred in 1998 when the largest America's most prestigious and management consulting-organization, McKinsey and Company's now famous publication reported hat "a battle over better talent is worth it". Their data emerged from a rigorous study of 77 firms across varied industries and almost 6000 executives as well as managers for a period of one year. This data however, was saturated with additional 20 case studies of firms perceived to be talent endowed $[8,9]$. The conclusion of McKinsey's research highlighted that the most crucial corporate resource for the span of 20 years ahead would be those with technological literacy, global astuteness and acute operational agility. In short, they are the embodiment of smartness and sophistication. To McKinsey, talent represents the summation of one's capabilities, skills, learning, attitude, judgment and drive [10]. In other words, talent connotes the best the brightest [11]. Also viewed talent as high-impact group of elite, yet individuals with high maintenance capable of dealing with complex situations but are more complex themselves. In contrast, some organizations use the concept synonymously to represent the entire workforce whilst others refer to the entire workforce when used [12]. David Ulrich, a professor and HR guru approached the concept holistically, when he defined it as "the possession of the required knowledge, skills, and cherished norms presently and beyond as employee puts in time and effort towards the success of the organization and at the same time enthused by what they do." Ulrich further dissect the talent war as the aggressive search for individuals with the needed competencies and commitment towards their job because it gives them a sense of purpose and fulfillment and more also, the relentless willingness to develop and keep them when found. In spite of these definitions, McKinsey's became more pervasive after their study found $89 \%$ of respondents agreeing that talent attraction is even more difficult than it was in three years ago with $90 \%$ admitting that their retention leaves the HR in a state of endless brainstorming. In their publication entitled "The old reality replaced by new reality" explained as the era of moving from "people needing companies" to "companies needing people", it is highlighted that the future demand for talent would hike leading to a costly battle [8]. The study also found that the firms that are up to the task on talent management are delivering greater value to their shareholders with an improvement in operational productivity as well as sales revenue and profit compared to average performers.

Nonetheless, the critical reasons that make the issue of talent war more alarming and bewildering challenge that all competitive organizations need to address reside in: improved longevity with dramatic decline in birth rate; gradual exist of the baby boomers; spurt of globalization; shift from product-based to knowledge-based economies and finally, rising employee consumerism.

To begin with, in countries like Italy, Germany, China, Singapore and Japan the average number of children per woman are below the replacement rate of 2.1 offspring per woman in order to maintain population levels [13]. Eventually, this would lead to gradual reduction in the human capital in these countries over a period of time. And truly, they cannot flee its stunt impact making the talent battle even tougher for firms in these nations.

Besides, as the baby boomer advance in age with Europe and Japan already coming under the weight of the dramatic shifts in population profiles, it is simply impossible for businesses to stay aloof and just watch on. The die is cast and organizations that respond aptly might be above the ship-wrenching tides of the talent battle yet to roll. With $7 \%, 9 \%$ and $14 \%$ decline in ages 15-64 within Germany, Italy and Japan respectively, a bigger picture unfolds and the changes could be fast and abrupt [13].

In addition, spurt in globalization as well as tremendous economic integration across the globe, inevitably impact the supply of labor and consequently the talent war. The economic barriers at varied geographical locations are losing their threat potency and grip as nations are getting more flexible with their international interaction laws than before. This however, is driven by labour market integration which in turn derives resilience from foreign direct investment with value of $\$ 1833$ billion as of 2007 despite the financial down-turn [13]. Interestingly, in countries like Malaysia and Mexico FDI is linked with the import of best managerial and technological practices which heightens the labour power of employees. Typically, China multinational firms had to deal with $20-30 \%$ year turnover and poaching of executive staff [14-16].

Furthermore, Johnson et al in a study found that the services sector globally provides $42.7 \%$ jobs compared to $34.9 \%$ produced by agriculture and $22.4 \%$ generated by industry with even larger value as $71.5 \%$ relative to developed economies. This radical shift from product-based to knowledge-based economies in transformation of business trends is inimical to the global war for talent. And it gets more frightening as service economies pursue investment in areas of human and intangible assets [12].

Finally, the growing speed of technology and increase in data accessibility is creating a breed of employees who are largely informed about employment markets, options and opportunities, thereby 
complicating the hurdle to find and hire top talents [17]. For instance, the rather linear trend of work life cycle- education, job, retirement, it now gets interwoven where the period of education, job and recreation intertwined progressively along lifespan [18].

How does effective employee engagement meet this mind boggling business challenge that robs firms of their best profitability- battle over the brightest and the best? The researchers' line of argument is substantively supported by the literature in critical analysis from the firm's as much as the employee's perspective. To start with, the concept employee engagement is relatively green and still finding its footings in both business and academic literature. But its linkage to various organizational outcomes such as turnover, customer loyalty as well as performance error [19] safety, profitability and customer focusedbehavior is on-going [20]. The current popularity of engagement is schematically represented in Table 1 . In spite of the impressive outlook of the figures available, it is in sharp contrast to engagement publication available in PsychINFO, the leading database of scholarly publications in Psychology with the low values indicated [21].

Kahn [22] as the first to predict a co relational link between employee engagement and firm outcome levels, did so on the premise that employees work for other reasons aside their remuneration. $\mathrm{He}$ defined employee engagement as the manner of coordinating members' self to the roles of their works and essentially expressing themselves cognitively, emotionally and physically relative to their role performance. Effective employee engagement saves proactive firms from the war for talent in various matrixes.

First and foremost, based on the research findings of the Corporate Leadership Council it had been discovered that the highly engaged employees are $87 \%$ more likely to stay and work for their organization. Similarly, it had been found that more than half of the disengaged employees would be willing to abandon their current employer for another firm. Meanwhile, only $25 \%$ of highly engaged employees have an intention to leave their current job [23] and the impact of retention on firm's bottom line is significant intriguing [24]. Also, [25] found a positive correlation between employee engagement and the brand value of a firm. For instance, in the year 2005 when it was reported of Walmart's unfair treatment of employees, the news went viral because most employees and customers persistently discussed the issue. This affected the brand reputation and eventually its equity. And most employees if not all would like to work for a company with great brand value [26]. More also, it has been highlighted that one of the main factors of consideration when employees look out for a firm to work for is the serenity, conduciveness and safety of the work environment. Consistently, research findings have indicated a relationship between employee engagement and safety results. In meta-analysis by [27], it was brought to the fore that the top $25 \%$ of highly engaged employees experienced $49 \%$ less issues of safety. In the same vein, the findings revealed $41 \%$ less client safety incidents among most engaged employees within the health sector. Furthermore, [28] contends based on the findings of a study among 500 Junior High Schools. The results touched on inferiority complex as an answer to the lingering question why most youngsters prefer to stay out of school. And this explains why

\begin{tabular}{|l|c|c|c|c|}
\hline \multirow{2}{*}{} & \multicolumn{2}{|c|}{ The Internet } & \multicolumn{2}{c|}{ Psych INFO } \\
\cline { 2 - 5 } & Google & Google scholar & Anywhere & In Title \\
\hline Employee Engagement & 626000. & 1120 & 12 & 35 \\
\hline Work Engagement & 21400 & 785 & 20 & 66 \\
\hline Total & 645130 & 1898 & 32 & 1000 \\
\hline
\end{tabular}

Source: Bakker and Leiter (2010)

Table 1: The Popularity of Engagement. top companies such as Intel, Apple and Walmart promote a culture that encourages transparency, free flow of information and teamspirit. They also enforce the pattern of bridging the traditional gap that long existed between employees and their superiors [29]. Finally, [30] describes the HRM unit of every competitive organization as the engine house since the implemented policies determine the direction of the entire firm. No wonder firms without employee-centered policies though welcome gifted talents via the front door, those talents escape through the back door even long before it is noticed. Meanwhile, one of the tools that fix employee engagement swift and smart is the HR policies enacted by the firm. It is against this backdrop that the researchers believe there is no better time for this study relative to its relevance and competitive strategy.

\section{Summary}

In sum, the field of employee engagement is steadily gaining the attention of researchers and human resource practitioners as available evidences from findings turn to highlight its niche potentialities. But more essentially, as the battle for talents intensifies, it arouses a natural awakening among firms to explore more novel zones for competitive advantage and core competences. On this premise, the potential winners of the "war" are not the mightiest but the meekest; not the most powerful but the most passionate firms driven in the spirit of employee centeredness. Thus, the main research question is: how explorative could effective employee engagement be in addressing the war for talent?

\section{Methodology}

\section{Procedure and sample}

In collection of the primary data, the researchers employed simple random sampling which is defined by [31] as a random selection from the sampling frame which could be online based, computer generated, or random number table usually generated manually. It was crucial however that the survey was carried out based on three main criteria as guiding rule: In the first place, all participants were employees who have worked with the company for at least a year. Secondly, they all have a permanent working appointment with MTN Ghana. Finally, they experience direct or indirect supervision from their superiors to whom they are accountable. Having carried out a rigorous data cleaning (e.g. looks out for repeated records, ambiguous values, and limited time of survey completion), a sample of 137 employees was reached.

The gender classification in the research instrument after analysis produced a summation of $82(60 \%)$ male and $55(40 \%)$ female of the workforce of MTN Ghana. Chunk of the employees engaged by MTN Ghana are young adults, within the age range of 26-30 years which constitute $75(55 \%)$ of the employee aggregate whilst those above 30 years and those between $20-25$ years were 39 (28\%) and 23 (17\%) respectively. Most of the employees are executive position holders $58(42 \%), 30(22 \%)$ are heads of departments, $17(12 \%)$ are junior executives, $17(12 \%)$ are experts in management training, $9(7 \%)$ as assistant managers and $6(5 \%)$ with professional qualification of managers.

\section{Data collection}

The design of the research instrument took into account the exposition from the literature with 35 items specifically fashioned to examine the extent to which effective employee engagement is linked to powerful talent management. For instance, the questionnaire intends to address employee direct needs such as work resources as well as 
indirect ones like relationship with supervisors and conduciveness of the work environment. Moreover, the culture of the organization; human resource management practices and the satisfaction level of employees were closely assessed. The 5-Point Likert scale measurement was used in the development of the research instrument. Likert scale is one of the most commonly used scaled-response in survey design in recent times. The three main reasons why the researchers adopted the 5-point Scale as explained by includes: the argument that respondents in a survey might genuinely feel neutral about a given statement, and the research instrument might be predisposed to respondent bias as a result of the absence of a neutral midpoint, also, neutrality is a legitimate opinion that cannot be overruled among respondents. It is inevitable except that a researcher is not interested in neutral opinion. Finally, a nice midpoint is usually offered by 5-Point Scale. The 3 rating is exactly in the middle and it is an indication of mixed satisfaction or neutrality. The two most emphasized ethical behaviors in research conduction which include: confidentiality and informed consent underpinned the data collection process [32].

\section{Analysis}

The researchers hugely engaged the quantitative approach [33] with adept focus on capturing both participants' data and also protecting its accuracy and then, to integrate the results with theoretical findings. For the purposes of validity and reliability, the instrument was put through a meticulous scrutiny based on the underpinning logic. Establishing validity through logic implies the justification of each question in relation to the objectives of the study with sufficient priority on brevity, simplicity, and disambiguated sentences [34]. The analysis involved the usage of version 20 of IBM's SPSS as well as Microsoft Windows Excel.

This was preceded by data cleaning which is one of the most crucial and initial steps among the routines of processing a given data. The process was void of any missing data from the source file therefore heightened the credibility and confidence in the data. The prime goal of reliability test was to assess the internal consistency of the instrument using the Cronbach's Alpha as evaluative tool. The reliability results of Cronbach's Alpha vary between 0 and 1 and esteemed if the results of the Cronbach's Alpha transcend the minimum requirement of 0.7 [35]. Refer to Table 2 for details on reliability results.

To ensure effective interpretation of the data, the items were appropriately coded (1=Strongly Agree; 2=Agree; $3=$ Neutral; $4=$ Strongly Disagree and $5=$ Disagree). The overall mean for each of the variables (both independent and dependent) provides a summative disposition of respondents' views towards that particular variable [36]. This implies that the responses or views of respondents towards a particular variable can either be positive or negative depending on the magnitude of the response towards that variable. In lieu of this, a mean below 2.5 in this study signals positivity in the overall tendency of respondents relative to that particular variable. On the contrary, a mean above 2.5 is an indication of negative perception of respondents towards that variable.

To further ensure that no possible gaps exist in the findings, skype interviews were also conducted with some of the employees to enrich the integration of the results. The interviews were carefully transcribed and analysed where specific themes were identified in support of the quantitative data. In sum, triangulation was the approach adopted by the researchers.

\section{Results}

The outcome of our investigation produced an explicit overview of employee engagement trend at MTN Ghana. The results captured the health of the work environment as sane and sound. With HRM practices in their most attractive package presented, the employeesupervisor relationship could not go haywire but to yield a cohesive bonding and compassionate reciprocity. Serving as an umbrella, the consistent culture of quality, safety and value for both employee and customer provides an irresistible shade under which most employees found their satisfaction. These were the evidences uncovered with respect to each engagement strategy purported for scrutiny. The facts found include: resilience of the engagement strategies, correlational values and finally, variation of demographic information on effective employee engagement.

The strategic employee engagement variables included in the research questionnaire had their findings summarized as depicted in Table 2 below. Each of these variables is explained in the light of the findings with acute focus on the aggregate mean and overall percentage agreement.

Apparently, the work environment was strategically included in the survey instrument to assemble views, opinions and responses of participants with reference to the serenity of the physical and social environment prevailing at the workplace of MTN Ghana. With reference to the HRM practices, it targets the views, opinions and responses of participants with reference to employee-centred policies, reward systems and other motivational packages available in the company and the extent to which they stir up engagement drives of the employees. The focus of this variable was mainly towards the solicitation of views, opinions and responses of participants with reference to cordiality, peace and tranquility that ensue among the workforce of MTN Ghana, especially employees and their superiors. The premise of this reinforcement was based on the literature that strong and buoyant relationship between the two parties impacts engagement effectiveness. The main aim of including this variable was to assemble views, opinions and responses of participants with reference to their enthusiasm and degree to which they feel excited about what they do. A culture of an organization, though, seemingly intangible is like the rudder of a ship. It steers the direction of the firm and creates a sense of belongingness for both employees and customers alike. Just like the other variables the opinions, views and responses regarding nurturing and cherishing

\begin{tabular}{|c|c|c|c|c|c|c|}
\hline \multicolumn{2}{|c|}{ Engagement variables } & \multicolumn{2}{|c|}{ Cronbach's alpha/No. of items } & \multirow{2}{*}{$\begin{array}{l}\text { Mean } \\
1.590\end{array}$} & \multirow{2}{*}{$\begin{array}{c}\text { Variable viability }(\%) \\
86.9\end{array}$} & \multirow{2}{*}{$\begin{array}{c}\text { Pearson Correlation } \mathbf{N} \\
.461^{\star \star}\end{array}$} \\
\hline 1 & Work Environment & 5 & .890 & & & \\
\hline 2 & HRM Practices & 6 & .814 & 1.600 & 91.4 & $.528^{\star *}$ \\
\hline 3 & Employee-Supervisor Relationship & 7 & .885 & 1.720 & 86.3 & $.530^{\star *}$ \\
\hline 4 & Job Satisfaction & 5 & .903 & 1.710 & 87.4 & $.468^{* *}$ \\
\hline 5 & Organizational Culture & 7 & .892 & 1.810 & & $.979 * *$ \\
\hline 6 & Overall means of engagement & & & 1.686 & 88.0 & \\
\hline \multirow[t]{2}{*}{7} & Engagement (MTN Ghana) & 5 & .778 & 1.710 & & \\
\hline & Total & 35 & .962 & & & \\
\hline
\end{tabular}


the values and norms that create the corporate identity are irresistibly embraced and accepted by most employees.

A critical look at Table 3 suggests that participants responses were almost the same irrespective of their gender, with means $=2.35$ and 2.32 respectively.

The t-value (.451) has a significance $(p)$ value (.633) which is greater than the alpha (0.05) confirming that the variation between the means is not significant. Therefore there is no significant difference in effective employee engagement with regards to the employee's gender at $5 \%$ level of significance. Table 4 contains the outcome of the ANOVA results. This is to examine possible variation in engagement levels with reference to age of employees.

Critical look at Table 4 suggests that the level of effective employee engagement does not differ with respect to age. However, the participants in the age group of 26-30 obtained the highest mean (2.5), with those in the age group of 20-25 obtaining the lowest mean (2.3). The obtained F-value (2.535) has a significant p-value of 0.43 which is greater than the alpha (0.05). This affirms that effective employee engagement does not vary with regards to employee's age at $5 \%$ level of significance.

The mean of 2.3 as indicated in Table 4 suggests that there is no significant difference in the level of effective employee engagement with respect to the marital status of employees at MTN Ghana. The obtained F-value (1.405) has a significant p-value of 0.373 which is greater than the alpha (0.05). This affirms that effective employee engagement does not vary with regards to employee's marital status at $5 \%$ level of significance.

The means of years of working experiences have not differed significantly from one another. However, having F-value of 6.323 with p-value of .000 which is less than the alpha (0.05), confirm the conclusion that effective employee engagement varies with years of working experience at $5 \%$ significant level. And this could explain the fact that as employees advance on their job, their level of confidence thrives, build stronger emotional ties with colleagues and job setting and are more willing to make sacrifices in their firm's interest.

The mean of 2.4 as indicated in Table 4 suggests that there is no significant difference in the level of effective employee engagement with respect to educational background of employees at MTN Ghana. The obtained F-value (5.551) has a significant $\mathrm{p}$-value of 0.05 which is equal to the alpha (0.05). This affirms that effective employee engagement

\begin{tabular}{|c|c|c|c|}
\hline Gender & Mean & T & Sig. (2-tailed) \\
\hline Male & 2.32 & .451 & .633 \\
\hline Female & 2.35 & & \\
\hline Total & 2.33 & & \\
\hline
\end{tabular}

Table 3: The T-test results. does not vary with regards to employee's educational background at $5 \%$ level of significance.

It could therefore be concluded that among all the key demographic data examined by the researchers, it is insightful to find that employees get more engaged as they gain sufficient experience.

\section{Discussion}

This study evaluates effective employee as an antidote in dealing with the mind boggling challenge of the unending war over talent using a telecommunication firm, Mobile Telecommunication Network (MTN) Ghana. The epic awareness of increasingly complex and hyper competitiveness in global economy creates the acute sensitivity to re-evaluate the criticality of managing talent as a resource to firms' longevity. Picking on a thought provoking statement by the CEO of Siemens, Joe Kaeser which says: the rate of continuous rise in talent scarcity is beating up its predictable estimates and requires the fullest management to avert the trends. According to Teng, one of the most strategic tools in combating the talent is talent engagement [36]. It is in this light, that the confidence of the researchers is anchored that the insightful findings could trigger a shift that gives firms vigour to nurture their own core competences, thus competitive advantage that would be firm-specific.

Given the primary data above, the obtained mean for work environment (1.590) indicates employee positivism towards the variable. An agreement level of $86.9 \%$ yielded by same variable confirms its viability and the confidence employees have in the work environment of the "Mobile telecomm giant". Alongside, the Pearson's correlation coefficient $(\mathrm{r}=0.461)$ yielded a positive a correlation though it's the smallest correlational value obtained.

Imperatively, the HRM practices of every firm have the propensity to invoke passion or bitterness among employees towards the firm and its very vision. For instance, when the transformational leadership style was adopted by Lee Kun-hee during his era as CEO of Samsung Company, it became imperative that strong employee-supervisor relationship received a boost and was inevitably infused into the culture of the organization [37].

The HRM Practices obtained a mean of mean equivalent to 1.600 . This signifies participants' general attitude concerning the HRM Practices at MTN Ghana is potent, proactive and highly embraced. Similarly, the rate of viability indicates homogeneous signal with the overall engagement trend (91.4\% and 88.0$)$. The Pearson's Correlation Coefficient for this variable in relation to the dependent variable is positive $(r=0.528)$, moderately correlated and third highest value produced.

Surprisingly, the impact of networking between employees and

\begin{tabular}{|c|c|c|c|c|c|c|c|c|}
\hline & \multicolumn{2}{|c|}{ Age } & \multicolumn{2}{|c|}{ Marital Status } & \multicolumn{2}{|c|}{ Years of experience } & \multicolumn{2}{|c|}{ Educational Background } \\
\hline & & Mean & & & & Mean & & Mean \\
\hline & $20-25$ & 2.3 & Single & 2.3 & Less than 3 years & 2.3 & $\mathrm{PhD}$ & \\
\hline & $26-30$ & 2.3 & Married & 2.3 & $4-6$ years & 2.5 & Master & \\
\hline & Above 30 & 2.4 & Divorced & 2.4 & $7-9$ years & 2.1 & Degree & 2.4 \\
\hline & & & & & $\begin{array}{c}10 \text { years and } \\
\text { above }\end{array}$ & 2.4 & Diploma & 2.5 \\
\hline & Total & 2.4 & Total & 2.3 & Total & 2.3 & Total & 2.4 \\
\hline $\mathrm{F}$ & \multicolumn{2}{|c|}{2.535} & \multicolumn{2}{|c|}{1.404} & \multicolumn{2}{|c|}{6.323} & \multicolumn{2}{|c|}{5.551} \\
\hline Sig & \multicolumn{2}{|c|}{.43} & \multicolumn{2}{|c|}{.373} & \multicolumn{2}{|c|}{.000} & \multicolumn{2}{|c|}{.05} \\
\hline
\end{tabular}


their superiors is contingent on the level of cordiality existing between the two parties. A flat pattern of organizational structure encourages coherence and cooperation which promotes an insightful learning atmosphere. Evidence shows an interview results where employees pointed that though they had an opportunity to move to better paying firms, the amicable interaction with their supervisors denied them the confidence to quit [38].

The findings of this study produced a primary data of 1.720 indicative of the resilience demonstrated by employee-supervisor relationship. In a critical comparison of the viability values of 'employee-supervisor relationship' and 'engagement at MTN Ghana' brings to light the coherency in workers opinions (86.3\% and $88.0 \%)$ as uncovered.

In support of this assertion, the Pearson correlation coefficient $(\mathrm{r}=0.530)$ though this variable is moderate, it is the second highest correlated value. Due to the evidential support from literature regarding the fit between job satisfaction and employee engagement informed the decision for its inclusion as a controlling variable [39]. The survey has a mean of mean of 1.710 obtained in favour of employees' job satisfaction. Close analysis of 'Job satisfaction' and 'Engagement at MNT Ghana' in terms of their viability values shows $87.9 \%$ and $88.0 \%$ respectively. The Pearson correlation coefficient shows a positive and moderate value $(r=0.468)$, however Organizational Culture has been come an intricate element of business strategies as a result of the complexities, sophistications, and the global call. For instance, Egypt Airline has been competitive in the airline industry over the years, especially in most destinations in Africa for its culture of affordability. This culture singles out the company among its cohort with its target customers as middle and lower class customers [40]. Several studies have indicated that the prevailing culture in a particular organization determines the breed of employees attracted to that company and how long they stay [41].

Obtaining a mean of mean of 1.810 signifies a positive attitude of most employees towards 'Organizational culture' in the company whilst the figures for variables viability equate $84.4 \%$ and $88.0 \%$ respectively. To buttress this assertion, the Pearson correlation coefficient shows a positive and very strong value $(\mathrm{r}=0.979)$. This is the highest correlated variable among the five independent variables included in this research. It turns to announce that as much as employees cite positive views towards the culture of the organization, they also believe it has a very strong relationship with the dependent variable. In order to formulate a robust argument saturated in empirical evidence, the talent scarcity index of the selected Asian (presumed to form the chunk of the global population) nations: China, India, Singapore, Indonesia and Malaysia are shown in Table 5 .

Assessing the intensity and progression of the talent need in the countries of selection, it is quite obvious that though Singapore has good talent retention rate, the impressions of outside talents dangle. As India seem to be doing slightly better, the struggle of Indonesia and Malaysia speaks louder than could be concealed. Even, China the supposed "hub of talent" still feels the impact of the war. The evidence had been further highlighted in Weiss and MacKay's insightful book, "The talent advantage".

Surprisingly, the survey has a mean of mean (1.710) obtained as the summative performance of the overall employee engagement at MTN Ghana given the data analysis.

The analysis has also revealed the top most exhibited engagement characteristics among employees in the company as 'Achiever
Tendencies' and 'Energetic Disposition'. It was followed by 'Employee Proactivity' then, 'Active Involvement' and then 'Organizational pride'.

\section{Radical implications}

As proven from the literature, the underlying forces that underpin talent attrition and mobility are inherent within the physical, social and psychological environment. Other factors include degree of satisfaction derive from the job and the smoothness of the top-bottom relationship. Contrary to these is the brand image which is contingent on the culture of the firm as well as the HRM practices.

Yet, the impact of stress and discomfort caused by the physical working environment could be eliminated to large extent by investing sufficiently mental, social and work-related resources into the design of the work setting. Essentially, there is the need for moderation and emphasis on both organizational and individual interests which usually underpins the motivation and drive to achieve. In order to give weight and substance to this view [42], deepens the urgency and criticality to prioritize employee safety and welfare policies. Aside, the power of employee recognition is paramount. It is believed that employees with high positive esteem usually abound in confidence which enhances efficiency and accuracy. And mostly the confident employees have echoes firm's most dependable human asset.

\section{Conclusion}

This study carefully examined and evaluated in detail the core employee engagement strategies in mitigating the war over talent recently. The researchers adopted a quantitative analysis in assembling the views of employees and drawing meaningful conclusions via descriptive and inferential statistics. In order to authenticate and enrich the findings of the survey, interviews were conducted to conceal possible gaps. The researchers through rigorous literature review found the core engagement strategies as: work environment, HRM Practices, employee-supervisor relationship, job satisfaction, and organizational culture.

The analysis of the data gathered indicated that all the engagement strategies of the company are in good shape and more vibrant. This turns to explain the unparalleled performance of the company in its industry of operation. However, the greatest enemy of the company's current achievement is the tendency to be complacent.

In order to avert becoming a victim in the talent war, MTN Ghana must make every effort to stay abreast with the commitment pattern of her employees. This can be achieved through periodic assessment of employees' opinions and picking their thoughts on probable dissatisfied matters relative to the organizational management. As employees are radically engaged via strategic human resource management, the trend of attrition would ultimately fall to the lowest limit possible, thereby strengthening the corporate brand and its preference among clients. In practice, the talent war is immune to prevention yet, the

\begin{tabular}{|l|c|c|c|c|}
\hline & $\begin{array}{c}\text { Talent } \\
\text { identification }\end{array}$ & $\begin{array}{c}\text { Talent } \\
\text { attraction }\end{array}$ & $\begin{array}{c}\text { Talent } \\
\text { retention }\end{array}$ & $\begin{array}{c}\text { Overall } \\
\text { scarcity }\end{array}$ \\
\hline China & $53 \%$ & $80 \%$ & $83 \%$ & $60 \%$ \\
\hline India & $55 \%$ & $72 \%$ & $72 \%$ & $62 \%$ \\
\hline Indonesia & $63 \%$ & $80 \%$ & $83 \%$ & $70 \%$ \\
\hline Malaysia & $68 \%$ & $87 \%$ & $84 \%$ & $77 \%$ \\
\hline Singapore & $66 \%$ & $75 \%$ & $88 \%$ & $90 \%$ \\
\hline
\end{tabular}

Source: Wellins et al, 2012

Table 5: Distribution of the talent war in Asia. 
Citation: Kaliannan M, Adjovu SN (2015) Wining the Talent War via Effective Employee Engagement: A Case Study. J Bus Fin Aff 3: 132. doi:10.4172/2167-0234.1000132

smart companies have the option to escape even its fiercest impact via effective employee engagement.

\section{References}

1. Nohria N (1999) The war for global talent. Chief Executive Magazine 16.

2. Mendenhall ME, Osland JS, Bird A, Oddou GR, Maznevski ML (2008) Globa Leadership: research, practice, and development. Routledge, London.

3. Yanadori Y, Kato T (2007) Average employee tenure, voluntary turnover ratio, and labour productivity: evidence from Japanese Firms". Int J of Hum Resour Mange 18: 1841-1857.

4. Somaya D, Williamson IO, Lorinkova N (2008) Gone but Not Lost: The Differen Performance Impacts of Employee Mobility Between Cooperators Versus Competitors. Acad M J 12: 13-27.

5. Nahapiet, Ghoshal S (1998) Social Capital, Intellectual Capital and the Organizational Advantage. Acad Manage Rev 23: 242-266.

6. Heidrick G, Struggles J (2007) Mapping global talent: Essays and insights. Economist Intelligence Unit Ltd, Switzerland.

7. Smith F (2008) Workspace: companies will keep top staff. Australian Financial Review 50: 33-45.

8. Chambers E, Foulon M, Handfield-Jones H, Hankin S, Michaels E (1998) The war for talent. The McKinsey Quarterly 3: 44-57.

9. Axelrod B, Handfield-Jones H, Welsh T (2001) War for talent, part two McKinsey.Quarterly 2.

10. Michaels E, Handfield-Jones $H$, Axelrod B (2001) The war for talent. Harvard Business School Press, Boston, MA.

11. Robertson A, Abbey G (2003) Managing talented people. Momentum/Pearson Education, Essex.

12. The Economist (2006) Survey: talent. The Economist.

13. United Nations Conference on Trade and Development (UNCTAD) (2008) World investment report: transnational corporations and the infrastructure challenge. United Nations, New York and Geneva.

14. The Economist (2007) Briefing: manpower: the world of work.

15. Farrell D, Grant A (2007) China's looming talent shortage. Sage Publications Newbury Park.

16. Prieur M (2007) In the same boat: China and India bogged in shallow talent pools. New York: McGraw-Hill

17. Potter E (2005) Part 1: changing workforce demographics and management challenges.

18. Pfeffer J, Sutton R (2006) Hard facts, dangerous half-truths, and total nonsense: profiting from evidence-based management. Harvard Business School Press, Boston, MA.

19. Gonring MP (2008) Customer loyalty and employee engagement: an alignment for value. J Bus Strategy 29: 29-40.

20. Harter JK, Schmidt FL, Hayes TL (2002). Business-unit-level relationship between employee satisfaction, employee engagement, and business outcomes: A meta-analysis. J Appl Psychol 87: 268-279.

21. Bakker AB, Leiter MP (2010) Work engagement: A handbook of Essential Theory and Research, New York Press.

22. Kahn WA (1990) Psychological condition of personal engagement and disengagement at Work. Acad Manage J 23: 692-723

23. Towers Perrin (2003) Working Today: Understanding What Drives Employee.

24. Haid M, Sims J (2009) Employee Engagement: Maximizing Organizational Performance via Right Management.

25. Taleo Research (2009) Alignment Drives Employee Engagement and Productivity.
26. Eisenhardt K, Schoonhoven CB (1990) Organizational growth: linking founding team, strategy, environment, and growth among U.S. semiconductor ventures. Administrative Science 35: 504-529.

27. Harter JK, Schmidt FL, Killham EA, Agrawal STL (2009) Meta-Analysis: The Relationship Between Engagement at Work and Organizational Outcomes.

28. Nink M (2009) Employee disengagement plagues Germany, Good workers and bad management crimp the country's productivity and GDP, Gallup Management Journal.

29. Hobfoll (2002) A program for Africa's computer people. Science and Technology 19: 79-89.

30. Brockner J, Grover S, Reed T, De Witt R (1996) Layoffs, Job Insecurity and Survivors' Work Effort: Evidence of an Inverted-U Relationship. Acad Manage J 33: 413-435.

31. Thomas RM, Brubaker DL (2007) Theses and Dissertations: A guide to Planning, Research and Writing London: Corwin

32. Tait M, Padgett MY, Baldwin TT (1989) Job and life satisfaction: A re-evaluation of the Strength of the relationship and gender effects as a function of the date of the study. J Appl Psychol 74: 503-507.

33. Crewell JW (2009) Research Design: Qualitative, Quantitative, and Mixed Methods Approaches, London: Sage.

34. Barney JB, Hesterly WS (2008) Strategic Management and Competitive Advantage: Concepts and cases, USA: Pearson Education Incorporated.

35. Haslam SA, McGarty C (2003) Research Methods and Statistics in Psychology, London: Sage.

36. Morgan D (1998) Practical strategies for combining qualitative and quantitative methods: Applications to health research. Qualitative Health Research 8: 362 376 .

37. Teng A (May 2007) Making the business case for HR: Talent management aids business earnings. HRO Today magazine.

38. Baruch Y, Budhwar P, Khatri N (2006) Brain drain: inclination to stay abroad after studies. J World Bus 42: 99-112.

39. Spector PE (1997) Job Satisfaction: Application, Assessments causes, and consequences, California, Sage Publications.

40. Barney JB, Hesterly WS (2008) Strategic Management and Competitive Advantage: Concepts and cases. USA: Pearson Education Incorporated.

41. Lane AM, March JG, Sutton RI (2001) attitudinal organizational commitment and job performance: a meta-analysis. Journal of Organizational Behavior 23 257-266.

42. Myer (1989) Driving performance and retention through employee engagement, Corporate Leadership Council. 